\title{
Incidental Dural Tears During Lumbar Spine Surgery: A Retrospective Case Study of 84 Degenerative Lumbar Spine Patients
}

\author{
Ronen Blecher, Yoram Anekstein, Yigal Mirovsky \\ Department of Orthopedics, Assaf Harofeh Medical Center, Zerifin, Israel
}

\begin{abstract}
Study Design: A retrospective case study.
Purpose: To retrospectively review all incidental dural tears (DTs) that occurred at a single institution, classify them anatomically and evaluate the clinical significance of each subgroup.

Overview of Literature: Dural tears are considered the most commonly encountered complication during lumbar spine surgery. In contrast to the high frequency of DTs, reports on the characteristic location and mechanism are sparse.

Methods: We retrospectively retrieved all cases of degenerative lumbar spine surgery performed over a 9-year period and classified all identified DTs according to two independent planes. The coronal plane was divided into lower, middle and upper surgical fields, and the sagittal plane into posterior, lateral and ventral occurring tears. Demographic and clinical variables were retrieved and analyzed to search for significant associations.

Results: From 2003 to 2011, 1,235 cases of degenerative lumbar spine conditions were treated surgically at our institution. In 84 operations $(6.8 \%)$, an incidental DT was either identified intraoperatively or suspected retrospectively. The most commonly involved location was the lower surgical field ( $n=39,46.4 \% ; p=0.002)$, followed equally by the middle and upper fields $(n=16,19 \%)$. In the sagittal plane, the most commonly involved locations were those in close proximity to the nerve root $(n=35,41.6 \%)$, followed by the dorsal aspect of the dural sac $(n=24,28.6 \%)$. None of the variables recorded was found to be associated with a particular location. Conclusions: In our series, incidental DTs were found to occur most commonly in the lower surgical field. We hypothesize that local anatomic feature, such as the lordotic and broadening lumbar dura, may play a role in the observed DT tendency to occur in the lower surgical field. In light of the high frequency and potentially substantial resulting morbidity of incidental DTs, a better characterization of its location and mechanism may optimize both prevention and management.
\end{abstract}

Keywords: Spine; Lumbosacral region; Incidental durotomy

\section{Introduction}

Incidental tears of the dural sac are considered to be the most commonly encountered complication of lumbar spine surgery [1], with a reported prevalence that var- ies from $1.8 \%$ to as high as $17 \%$ in some reports [2]. Incidental dural tears (DTs) can be noticed either intraoperatively, with the identification of an obvious tear, a leak of cerebrospinal fluid or both or can be suspected retrospectively due to the postoperative appearance of

Received Nov 13, 2013; Revised Jan 5, 2014; Accepted Jan 8, 2014

Corresponding author: Ronen Blecher

Department of Orthopedics, Assaf Harofeh Medical Center, Beer Ya'akov, Zerifin, 70300, Israel

Tel: +972-8-977-9434, Fax: +972-8-977-9434, E-mail: roblecher@gmail.com 
postural headaches, as well as a persistent clear drainage. Surprisingly, in contrast to its high prevalence, only a few comprehensive reports of incidental DTs in the literature are available [2-6], with most of the studies attempting to evaluate predictive factors and discuss treatment strategies. To the best of our knowledge, even fewer reports have referred to the predilection of incidental DTs to occur at a certain location [2] or have discussed a possible mechanism [1].

The objective of this study is to review all incidental DTs that occurred during lumbar spine surgery at a single institution in terms of anatomic location, clinical significance and possible contributing factors.

\section{Materials and Methods}

The study was performed retrospectively, by retrieving all cases of degenerative lumbar spine treated surgically at our unit, which were identified as having been complicated either intraoperatively or postoperatively with incidental DTs. The cases, performed over a 9-year period (2003-2011) at a single institution, were obtained by searching independently both the manual and the computerized data registries. Detailed hand-made illustrations (when available) in the manual registry, supplanted by the tear's description in the operative report, enabled the anatomic classification of the DTs (see the anatomic classification section below). Cases included in the study were those primarily affecting the lumbar spine and related to a degenerative pathology, in one of the following main etiological subgroups: disc herniation; stenosis; spondylolisthesis; post-laminectomy syndrome; deformity; and a combination. Case retrieval was not limited by patient age. Exclusion criteria were defined as cases suspected to involve any other than degenerative underlying pathology, such as infection, malignancy and metabolic disorders etc. Patient characteristics included age, gender and the presence of multiple co-morbidities (three and above). Operative variables included type (discectomy; decompression alone; decompression and fusion performed at a single level or more); duration; the presence of a resident; and the type of treatment given once the tear was identified. Postoperative data included the presence of any dural-tear associated complaints (e.g., postural headaches, nausea), drainage parameters (duration, amount on the first postoperative day, the total amount) and whether a revision surgery was eventually
Table 1. A suggested two-plane anatomic classification of dural tears

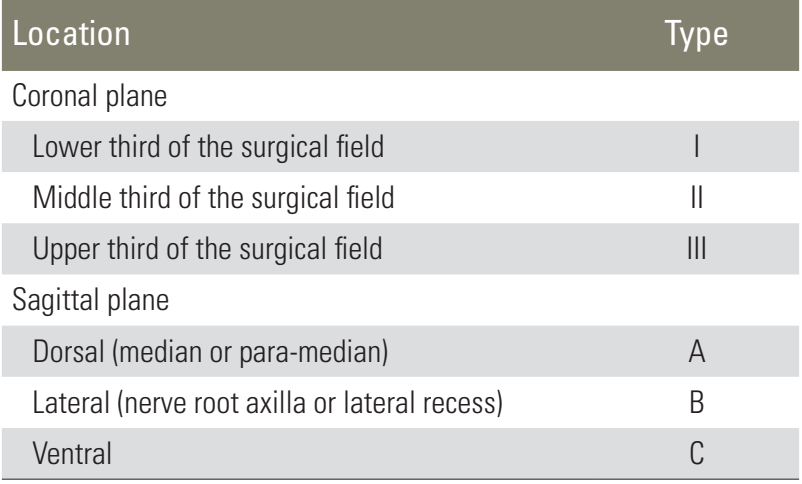

performed. All of the operations were performed in an open manner. Suction drains, when used, were placed below the fascia. On few occasions, the drains were converted to act on gravity only. This study was approved by the Institutional Review Board of the Assaf Harofeh Medical Center.

\section{Anatomic classification}

For the purpose of anatomic classification, the location of all identified DTs was determined (when applicable) in two independent planes (Table 1). In the sagittal plane, three main subgroups were identified (Fig. 1): type A, defined as posteriorly-located tears (either in a central or a paracentral location); type $\mathrm{B}$, defined as lateral tears (adjacent nerve root's axilla or at its recess); and type C, defined as tears involving the ventral aspect of the dural sac. In the coronal plane, the surgical field was divided into thirds (Fig. 2); and the tears were defined according to the level involved, being the lower (type I), middle (type II) or upper surgical field (type III). Anatomic borders between thirds were defined as the following. In cases of single level decompression, borders between thirds were defined as lines connecting the intersection of the pars with either the rostral facet joints (upper border) or the caudal facet joints (lower border). In cases of two-level surgeries, the intersection of the pars with the caudal facet joint of the rostral vertebrae was defined as the upper border; and the intersection of the pars with the rostral facet joints of the caudal vertebrae was defined as the lower border. Cases that either contained an insufficient description or a poorly detailed anatomic illustration were defined as undetermined. Similarly, operations in which the surgical-field size prevented determination of 


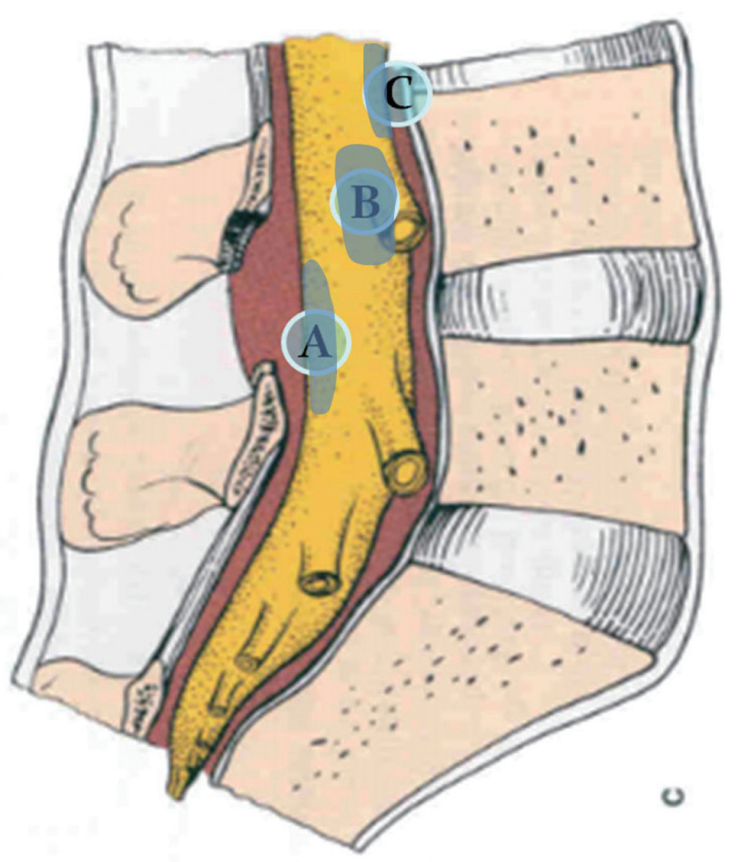

Fig. 1. An illustration classifying the sagittal surgical field into dorsal (type A), lateral (type B) and ventral (type C) occurring tears. the location were also omitted (e.g., a coronal location on a simple discectomy).

\section{Statistical analysis}

A simple chi-square test was initially performed to determine whether the identified DTs had the tendency to occur at a certain anatomic location. Subsequently, the Pearson chi-square test was performed in order to evaluate possible interactions between anatomic location and categorical variables. Finally, the one-way analysis of variance test was performed to evaluate interactions between anatomic location and numeric variables.

\section{Results}

During a 9-year period, from 2003 to 2011, a total of 1,235 cases of degenerative conditions of the lumbar spine were treated surgically at our unit. In 84 operations (42 women and 42 men; mean age 58.9 years; range 19 through 83 ),
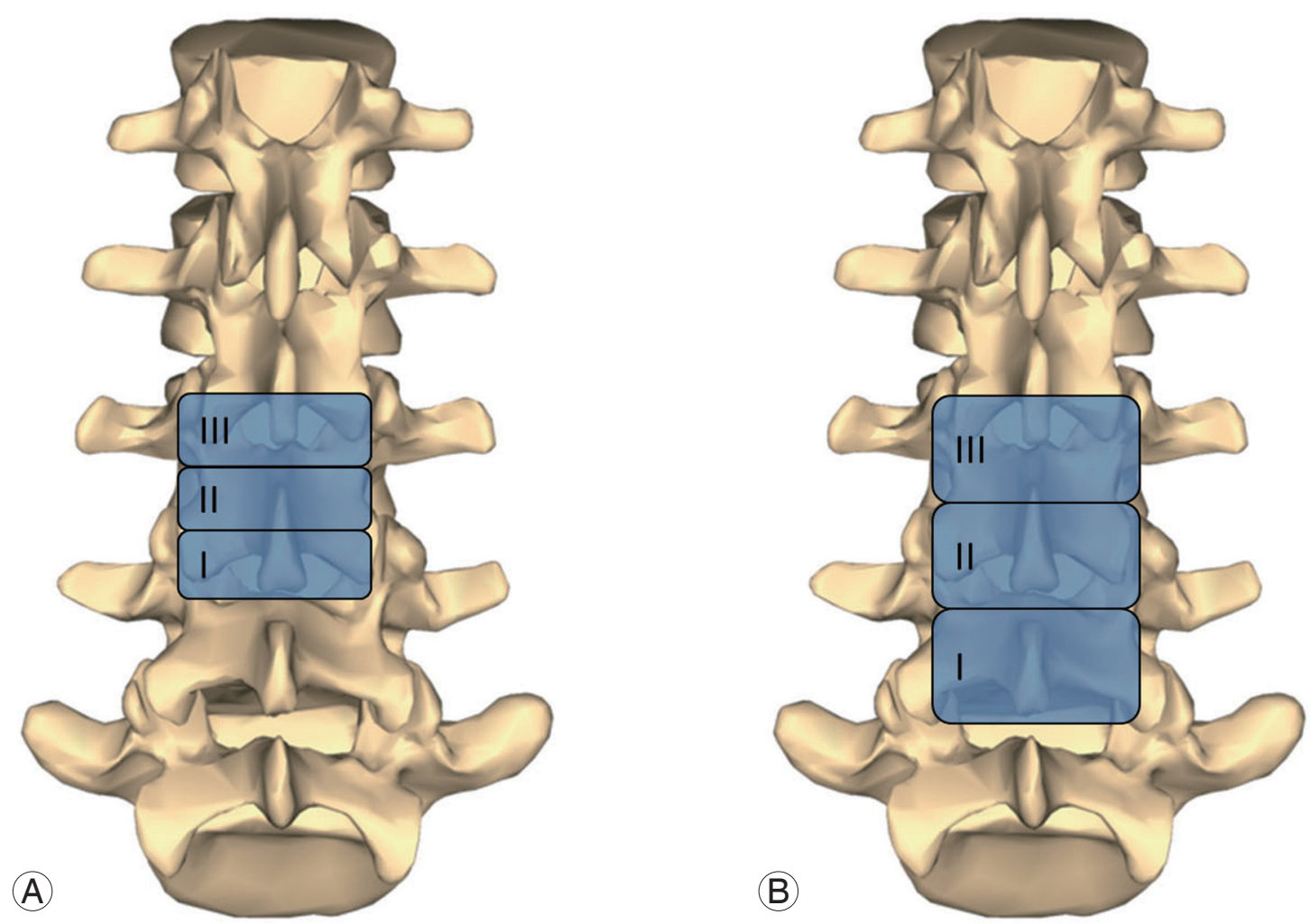

Fig. 2. An illustration classifying the coronal surgical field into upper (type I), middle (type II) and lower (type III) thirds. (A) Single level operation. Borders are defined as the lines connecting the intersection of the pars with either the rostral facet joints (upper border) or the caudal facet joints (lower border). (B) Two-level operation. The upper border is defined as the intersection of the pars with the caudal facet joint of the rostral vertebrae; and the lower border is defined as the intersection of the pars with the rostral facet joints of the caudal vertebrae. 
Table 2. A summary of the incidental dural tear according to anatomic location

\begin{tabular}{|c|c|c|c|}
\hline \multicolumn{2}{|c|}{ Coronal plane } & \multicolumn{2}{|c|}{ Sagittal plane } \\
\hline Surgical field & $\mathrm{n}$ & Location & $\mathrm{n}$ \\
\hline I. Lower & 39 & A. Dorsal & 24 \\
\hline II. Middle & 16 & B. Lateral & 35 \\
\hline III. Upper & 16 & C. Ventral & 6 \\
\hline Undetermined & 26 & Undetermined & 19 \\
\hline Total & 84 & Total & 84 \\
\hline$p$-value & 0.002 & $p$-value & 0.002 \\
\hline
\end{tabular}

an incidental DT was either identified intraoperatively or suspected retrospectively. The most commonly involved procedures were decompression and fusion, performed either at two levels or more $(n=26)$ or a single-level $(n=24)$, followed by single level decompression $(n=20)$ and simple discectomy $(\mathrm{n}=14)$. The rate of revision cases in which DT was noticed was $20.2 \%(n=17)$, compared to a total revision rate of $12.5 \%$; and a resident was present on 36 occasions (42.8\%), compared to an overall attendance rate of $44.2 \%$. There were no identified occasions that may have been directly associated with incidental durotomies, such as misplacement or slippage of screws and residual bony spikes etc. When a DT was noticed intraoperatively, treatment consisted primarily of suture alone $(n=46)$ or combined with the application of an adhesive sealant $(n=19)$. On 19 occasions, the tear was surgically irreparable. Persistent DT-related symptoms (i.e., headaches, nausea and continued clear drainage), despite conservative treatment, had necessitated revision surgery on two occasions.

\section{Anatomic location}

When the anatomic location was examined according to the classification described above, the lower surgical field (type I) was found to be the most commonly involved site of incidental DT on the coronal plane $(\mathrm{n}=39,46.4 \%$; $p=0.002$ ), followed equally by the middle and upper fields $(n=16,19 \%)$. In the sagittal plane, the most commonly involved locations were those in close proximity to the nerve root (type $\mathrm{B} ; \mathrm{n}=35 ; 41.6 \%, p<0.001$ ), followed by the dorsal aspect of the dural sac (type $A ; n=24 ; 28.6 \%$ ). Only 6 tears were found to involve the dural sac's ventral aspect. The anatomic location could not be satisfactorily determined on 19 (22.6\%) occasions in the sagittal plane and on 13 (15.4\%) occasions in the coronal plane. A summary of the incidental DTs according to anatomic location is presented in Table 2.

Statistical analysis designed to assess possible interactions between anatomic location and categorical variables (such as gender, operation type, intraoperative attendance of a resident) and the presence of postoperative durotomy-related symptoms failed to identify any significant associations. Incidental DTs were much more prevalent in revision surgeries and approached statistical significance $(p=0.07)$. A summary of the demographic details and related $P$-values is presented in Table 3 .

In terms of operative length, procedures in which a Type I DT was identified were generally lengthier, with a mean operative time of 230 minutes, compared to a mean length of 235 ( $p=$ non-significant [ns]). Operations with a Type I tear were marked by an increased amount of drainage on the first postoperative day (mean of $151 \mathrm{~mL}$, compared to mean drainage of $111 \mathrm{~mL}$ and $101 \mathrm{~mL}$ in types II and III, respectively), as well as with a prolonged drainage period (mean of 2.1 days, compared to mean of 1.7 days and 1.5 days in types II and II, respectively). None of these findings, however, was statistically significant. Finally, a similar evaluation of the DT location in the sagittal plane and all of the variables described above also failed to demonstrate any statistically significant interactions.

\section{Discussion}

The high frequency of incidental DT, rendering it the most commonly encountered complication in lumbar spine surgery and perhaps in spine surgery in general, has 
Table 3. A summary of the patient demographic details

\begin{tabular}{|c|c|c|}
\hline Characteristic & $\begin{array}{l}\text { Cases in which dural tears } \\
\text { were identified }(\%)\end{array}$ & $p$-value \\
\hline $\begin{array}{l}\text { Gender } \\
\text { Female } \\
\text { Male }\end{array}$ & $\begin{array}{l}42(50) \\
42(50)\end{array}$ & 1 \\
\hline $\begin{array}{l}\text { Age (yr) } \\
<30 \\
30-50 \\
50-70 \\
>70\end{array}$ & $\begin{array}{c}2(2.3) \\
12(14.3) \\
52(61.9) \\
18(21.4)\end{array}$ & 0.99 \\
\hline $\begin{array}{l}\text { Pathology } \\
\text { Disc herniation } \\
\text { Spondylolisthesis/stenosis } \\
\text { Post laminectomy syndrome } \\
\text { Adult deformity } \\
\text { Other (combined) }\end{array}$ & $\begin{array}{c}8(9.5) \\
53(63.1) \\
11(13.1) \\
6(7.1) \\
6(7.1)\end{array}$ & 0.88 \\
\hline $\begin{array}{l}\text { Surgery } \\
\text { Discectomy } \\
\text { Single level decompression } \\
\text { Posterior spinal fusion at a single level } \\
\text { Posterior spinal fusion at } 2 \text { levels or more }\end{array}$ & $\begin{array}{l}14(16.6) \\
20(23.8) \\
24(28.5) \\
26(30.1)\end{array}$ & 0.83 \\
\hline Revision surgery & $17(20.2)$ & 0.07 \\
\hline
\end{tabular}

been demonstrated repeatedly in various epidemiological studies [2]. Studies published thus far on incidental DT, however, have focused mainly on issues such as incidence $[7,8]$, contributing risk factors $[3,9]$, management [10$12]$ and long term sequelae $[2,4]$. Some of the risk factors suggested to play a role in the occurrence of DT include older patient age [13], complex [14] or revision surgery [2], a history of irradiation treatment [15] and an overall decreased experience level of the surgeon [13]. Although the potentially disastrous short-term sequelae of a cerebrospinal fluid leak, such as the formation of pseudomeningocele and meningitis, have been well described [16], a debate persists regarding possible poorer longterm clinical outcome in these patients $[17,18]$. Important local factors, such as anatomy, adhesions, issues of visualizations and the technique with which the decompression was carried out are known key factors in the occurrence of DTs. In a review by Bosacco et al. [1], several intraoperatively contributing mechanisms have been offered, including direct trauma to the dural sac (i.e., laceration), excessive nerve root traction and misplacement of instrumentation (pedicular screws in particular). Specifically, factors such as residual bone spikes, excessive ossification of the yellow ligament [19] and a scarred or redundant dura were also cited as possible predisposing factors, with the latter being strongly supported by the increased incidence of DT in revision surgery [4,11]. Basic research of the dura spinalis has been generally sparse, with a few published articles focusing mainly on its tensile strength $[20,21]$ and its variable elastin content [6].

In spite of the various factors discussed above, the significant propensity of the observed DT to occur more at caudal segments (type I tears) in the current study suggests that other local anatomic factors may have an additive role in the incidence of DT. For example, as the dura descends, it becomes both lordotic and broadened, in order to accommodate itself to the lumbar spine and the widening thecal sac. Patient's positioning may also enhance the lumbar lordotic curvature. Combined with a possible change in the dura's consistency in revision surgery (being either redundant or contracted), these factors may lead more easily to creating an impingement between an instrument placed horizontally (e.g., a Kerrison rongeur) and the lumbar dura. Whereas no significant associations were observed between the DT location and the clinical variables recorded, the clinical relevance of the current study lies in the identification of the significant propensity of the DT to occur at caudally-located 
segments.

\section{Study limitations}

The current study has several marked limitations. Having gathered partially-existing anatomic data is reflected by the relatively large number of undetermined anatomic locations, limiting the ability to determine statistical significance of observed associations between location and measured variables. The retrospective nature of the current study, which was performed at a single center, may further decrease its level of evidence.

\section{Conclusions}

According to our study, we suggest that in order to further decrease the likelihood of injuring the dura, an attention should be paid not only to obvious local factors such as adhesions and scar tissue, but also to the lordotic curvature, suggested to be related to the increased rate of DTs in the caudal-most segments. Simple measures such as decreasing the lumbar lordosis by positioning may serve this purpose. It is clear that further studies, be it anatomic, histologic or other, are needed to further decrease the rate of complication of incidental DTs in lumbar spinal surgery.

\section{Conflict of Interest}

No potential conflict of interest relevant to this article was reported.

\section{References}

1. Bosacco SJ, Gardner MJ, Guille JT. Evaluation and treatment of dural tears in lumbar spine surgery: a review. Clin Orthop Relat Res 2001;(389):238-47.

2. Wang JC, Bohlman HH, Riew KD. Dural tears secondary to operations on the lumbar spine. Management and results after a two-year-minimum followup of eighty-eight patients. J Bone Joint Surg Am 1998;80:1728-32.

3. Frymoyer JW, Wiesel SW, An HS. The adult and pediatric spine. 3rd ed. Philadelphia: Lippincott Williams \& Wilkins; 2004.

4. Dobreva EI. Stability of resistance to neguvon in the fly Musca domestica L. after cessation of laboratory selection. J Hyg Epidemiol Microbiol Immunol 1976; 21:274-9.

5. Eismont FJ, Wiesel SW, Rothman RH. Treatment of dural tears associated with spinal surgery. J Bone Joint Surg Am 1981;63:1132-6.

6. Kitchel SH, Eismont FJ, Green BA. Closed subarachnoid drainage for management of cerebrospinal fluid leakage after an operation on the spine. J Bone Joint Surg Am 1989;71:984-7.

7. Nasser R, Yadla S, Maltenfort MG, et al. Complications in spine surgery. J Neurosurg Spine 2010;13:144-57.

8. Tafazal SI, Sell PJ. Incidental durotomy in lumbar spine surgery: incidence and management. Eur Spine J 2005;14:287-90.

9. Teli M, Lovi A, Brayda-Bruno M, et al. Higher risk of dural tears and recurrent herniation with lumbar micro-endoscopic discectomy. Eur Spine J 2010;19:443-50.

10. Espiritu MT, Rhyne A, Darden BV 2nd. Dural tears in spine surgery. J Am Acad Orthop Surg 2010;18:537-45.

11. Khan MH, Rihn J, Steele G, et al. Postoperative management protocol for incidental dural tears during degenerative lumbar spine surgery: a review of 3,183 consecutive degenerative lumbar cases. Spine (Phila Pa 1976) 2006;31:2609-13.

12. Hodges SD, Humphreys SC, Eck JC, Covington LA. Management of incidental durotomy without mandatory bed rest. A retrospective review of 20 cases. Spine (Phila Pa 1976) 1999;24:2062-4.

13. Sin AH, Caldito G, Smith D, Rashidi M, Willis B, Nanda A. Predictive factors for dural tear and cerebrospinal fluid leakage in patients undergoing lumbar surgery. J Neurosurg Spine 2006;5:224-7.

14. Davne SH, Myers DL. Complications of lumbar spinal fusion with transpedicular instrumentation. Spine (Phila Pa 1976) 1992;17:S184-9.

15. Wiesel SW. The multiply operated lumbar spine. Instr Course Lect 1985;34:68-77.

16. Campbell WC, Canale ST, Crenshaw AH. Campbell's operative orthopaedics. 10th ed. St. Louis: Mosby; 2003.

17. Jones AA, Stambough JL, Balderston RA, Rothman $\mathrm{RH}$, Booth RE Jr. Long-term results of lumbar spine surgery complicated by unintended incidental durotomy. Spine (Phila Pa 1976) 1989;14:443-6. 
18. Saxler G, Kramer J, Barden B, Kurt A, Pfortner J, Bernsmann K. The long-term clinical sequelae of incidental durotomy in lumbar disc surgery. Spine (Phila Pa 1976) 2005;30:2298-302.

19. Epstein NE. The frequency and etiology of intraoperative dural tears in 110 predominantly geriatric patients undergoing multilevel laminectomy with noninstrumented fusions. J Spinal Disord Tech 2007;20:380-6.
20. Patin DJ, Eckstein EC, Harum K, Pallares VS. Anatomic and biomechanical properties of human lumbar dura mater. Anesth Analg 1993;76:535-40.

21. Runza M, Pietrabissa R, Mantero S, Albani A, Quaglini V, Contro R. Lumbar dura mater biomechanics: experimental characterization and scanning electron microscopy observations. Anesth Analg 1999;88:1317-21. 